\title{
- Guillermo Tovar de Teresa: en el corazón del alma mexicana
}

\author{
Alejandro González Acosta \\ Universidad Nacional Autónoma de México
}

Escribo bajo el peso aplastante de la pena y la sorpresa por la muerte de un gran amigo, Guillermo Tovar de Teresa (23 de agosto de 1956-10 de noviembre de 2013).

Muchos de quienes lo conocieron hablarán de su clara inteligencia, su asombrosa erudición, y su indeclinable compromiso con la cultura y la historia de México. Yo prefiero referirme al amigo entrañable que conocí hace más de 34 años en el Museo del Palacio de los Capitanes Generales en La Habana Vieja de 1979. Nos presentó el entonces embajador mexicano en la isla, Don Ernesto Madero Vázquez. Iba Guillermo junto con su hermano Rafael, recién nombrado director de Relaciones Culturales de la cancillería azteca. Y todos éramos jóvenes y gozosos veinteañeros. La amistad, que constituye una forma asexuada del amor, es instantánea y mutua, y así se manifestó. Se estableció de inmediato una corriente entre él y yo que se mantendría por más de tres décadas, y que retomamos en 1987 con mi llegada a México hasta hoy, cuando me golpeó la terrible noticia de su inesperada y absurda muerte, llegada por esas "redes sociales» que tanto le gustaban a Guillermo y que yo aborrezco, ahora más que nunca por ser la vía por donde me sorprendió este tremendo mazazo, más inconcebible aún por haber estado conversando muy grata y animadamente apenas dos días antes, largo y tendido, y sentirlo más vital que nunca, brillante y ocurrente, feliz de estar metido en nuevos proyectos, desafíos y sueños.

Hablamos de mil cosas, como siempre; entre otras, me dijo lo contento que estaba por una amistad redescubierta y renovada por don Emmanuel Carballo, con quien sostenía largas charlas sobre la literatura mexicana del siglo pasado, y además le había facilitado un ejemplar de la inencontrable edición primera (1966) de la novela Paradiso, de José Lezama Lima, enviada por el autor y corregida de su mano al gran crítico mexicano. "Mira si quiero y admiro a Carballo que hasta voy a verlo cada semana en su casa de Contadero, yo que apenas salgo de la mía», me afirmó. Y sí que lo quería, a él y a su mujer Beatriz Espejo. En esa misma conversación postrera, le comenté que andaba releyendo $L a$ vida en México, de Madame Calderón de la Barca, y encontraba una asombrosa 
coincidencia entre los dichos y los hechos de Valentín Gómez Farías y cierto muy notorio personaje de la política mexicana actual. "Tienes toda la razón -me dijolo conozco muy bien y es así de punta a cabo.»

Hombre de intensidades, Guillermo provocaba lo mismo una simpatía incondicional que una animadversión absoluta; todo, menos indiferencia. Cuando ingresaba en algún lugar, de inmediato las miradas se volvían hacia él y cuando comenzaba a hablar, de cualquier tema, "de lo divino o lo profano", atrapaba sin remedio. Su verbo florido y su erudición portentosa cautivaron desde temprana fecha a sus más cercanos familiares -sus abuelos, lo mismo los paternos Rafael Tovar y Dolores Villagordoa, que los maternos, Guillermo de Teresa y Josefina Wiechers- y a los visitantes de su hogar, entre ellos dos presidentes mexicanos como Adolfo López Mateos, que lo premió con una medalla a los 5 años y Gustavo Díaz Ordaz, quien lo nombró su asesor en temas de arte novohispano, a los 12. Infante prodigio, sin duda, pero no se malogró como otros, pues creció y continuó dando magníficos frutos. "Prefiero que me entiendan a que me amen", le decía a la edad de cinco años a sus asombrados padres contritos; "En esta casa no se come bien", le reclamó al padre, médico abnegado de muchos pacientes pobres que pagaban sus atenciones profesionales con pollos que surtían diariamente la mesa familiar. "Me voy con mi abuelo, que tiene un chef francés". Y el abuelo, encantado con la ocurrencia de su nieto. $Y$ los padres, profundamente conturbados. Hay que celebrar el tacto extraordinario y la generosidad sin límites de sus padres para aceptar desde muy temprana fecha la excepcionalidad y la difícil genialidad de este hijo. Lo cierto, además, es que en su edad adulta Guillermo detestaba comer pollo. $Y$ es que él era de una pieza, irrepetible: cuando lo hicieron -le decía- rompieron el molde. Ahora México será un poco más triste con su ausencia, ya sin esas llamadas telefónicas infinitas a cualquier hora. Thanatos cortó su hebra a los 57 años (apenas tres más de los que vivió su padre, fallecido a los 54 de edad).

Autodidacta "profesional» (sólo accedió a tomar algunos cursos de Derecho en la Universidad Autónoma Metropolitana), dio muestras de brillante precocidad: en 1973 publicó su primera obra, escrita a los 16 años, Noticias históricas de Chapultepec, Tacuba y Tacubaya (presentada por don Francisco González de Cossío); a los 22 años escribe Pintura y escultura del Renacimiento en México (prologada admirativamente por el gran don Diego Angulo). Poco después el enorme George Kubler anotaba en su presentación de México barroco, que «en cuatro décadas dedicadas a la docencia no he conocido a un estudioso tan precoz y tan dotado para el estudio de la historia del arte". Especialistas tan sólidos 
como Silvio Zavala, Octavio Paz, José Pascual Buxó, Jacques Lafaye, David Brading, Enrique Krause, Christopher Domínguez Michael y varios más, elogiarían también sus múltiples y altos talentos.

Guillermo Tovar ya era una leyenda en vida: el Niño Tovar, como le llamaba con profunda admiración don Fernando Benítez, asombró a propios y extraños desde tempranísima fecha. Su anécdota con el presidente Gustavo Díaz Ordaz, es de antología: el mandatario mexicano era amigo del abuelo de Guillermo y solía visitarlo. En una de esas oportunidades, el orgulloso patriarca quiso exhibir ante él las dotes de su nieto y pidió que lo trajeran. Díaz Ordaz, benévolo y sin esperar lo que vendría después, le preguntó: "A ver, niño, ¿qué puedes decirme de "El Caballito"?» Desde su ínfima altura el Niño de apenas diez años miró al presidente y le dijo: "Lo que usted mal Ilama "El Caballito", señor presidente, es la escultura ecuestre de Carlos IV, realizada por el artista valenciano Manuel Tolsá, autor también de obras como el Palacio de Minería..." Y continuó, inconteniblemente, por media hora más, acumulando nombres, fechas y hechos. Cuando terminó la "lección», asombrado y apabullado, el presidente le dijo: "Niño, con todo lo que sabes, debes ser mi asesor de arte novohispano". Y entonces vino lo mejor. "Muy bien, señor presidente, acepto su amable ofrecimiento... Pero me lo pone por escrito, porque en el colegio nadie me va a creer». En efecto, enmarcado discretamente en el muro de un acogedor salón de su residencia, puede verse el nombramiento firmado personalmente por el presidente de los Estados Unidos Mexicanos, Gustavo Díaz Ordaz, en papel membretado de la Residencia Oficial de Los Pinos: sus condiscípulos tuvieron que creérselo.

Menos difundida, por obvias razones, fue la que presenciamos varios amigos (Vicente Quirarte, Gonzalo Celorio, Salvador Díaz Cíntora [†] e Ignacio González-Polo, entre otros) y que lo pinta de un trazo: cuando se inauguró una nueva sede de la Academia Mexicana de la Lengua en su casona-facilitada por Alejandro Burillo Azcárraga- de la calle de Liverpool, asistieron los Reyes de España, el director de la Real Academia Española, Víctor García de la Concha, y el presidente Vicente Fox Quesada, con su esposa Martha Sahagún. Al terminar los discursos, ya de salida, Fox pasó por un salón donde estábamos los mencionados con Guillermo, quien desde varias semanas antes llevaba a cabo una intensa campaña en contra del proyecto foxiano de la llamada megabiblioteca "José Vasconcelos", verdadero elefante blanco de la administración del guanajuatense, a quien Tovar criticó, entre otros varios asuntos, por su ignorancia de que ya existía una Biblioteca Nacional de México (fundada por Benito Juárez 
en 1867, fue encomendada desde 1929 a la Universidad Nacional Autónoma de México en la figura del actual Instituto de Investigaciones Bibliográficas, que incorpora también la Hemeroteca Nacional). Salía Fox acompañado de los reyes hispanos, y de su esposa, flanqueado por la señora Sari Bermúdez, entonces presidenta del CoNaCulta y campechanamente le reclamó a Guillermo con su vozarrón ranchero: "Guillermo, deja ya de atacarme con mi proyecto de la Biblioteca Vasconcelos». Éste, ni corto ni perezoso, le espetó: "Vicente, el problema es que esta mujer -señalando a Sari Bermúdez en su mismo rostro- no entiende que no entiende». Fox quedó perplejo y enmudeció (cosa rarísima en él) pero el verdadero poema fue la expresión de la cara de la señora Bermúdez, quien miró a Tovar con un inequívoco odio, que tampoco lo turbó: "Sari, le dijo Guillermo con sabrosa displicencia, recuerda que a mí no me puedes tocar, porque soy primo de Santiago Creel...» (entonces secretario de Gobernación). Ellos prefirieron volver la espalda y poner pies en polvorosa. Así se las gastaba, pocas y buenas, Guillermo Tovar, de quien además de todo lo que se ha dicho y podrá decirse, habrá que agregar su valentía y sinceridad, no siempre bien recibidas. Hay que decirlo una vez más: Guillermo Tovar fue siempre un gran defensor de la Biblioteca Nacional de México, contra la ignorancia de algún presidente y la incomprensión de algunos otros, y fue suya la hermosa idea de crear la Asociación de Amigos de la BNM que aún está pendiente de llevar a cabo en su forma más plena y benéfica. Y fue generoso mecenas de otra Biblioteca de la cual se suele olvidar que también tiene carácter nacional: la de Antropología e Historia. A ella donó en fecha temprana, entre otros valiosos documentos, el conocido como "Códice Tovar», que ha tenido muy diversos percances en su historia.

La batalla más reciente donde Tovar aplicó sus saberes y afanes fue la del lamentable -espero que reparable también- estropicio precisamente de la escultura ecuestre de Carlos IV, realizada por Manuel Tolsá, conocida popularmente como "El Caballito", la misma que motivó su anécdota infantil ya apuntada. "Amigo de Platón, pero más amigo de la verdad", Guillermo no dudó en señalar el despropósito y exigir responsabilidades por semejante daño. Ojalá el amargo disgusto por este suceso no haya tenido nada que ver con su fallecimiento, pues muchos sabemos cuánto lo afectó, pero espero que como se anunció para el pasado viernes 18 de noviembre se conozca por fin el dictamen definitivo de los expertos y se deslinden responsabilidades. Confío que la partida de Tovar no sirva como distractor para que se rinda cuentas de ello, sino que por el contrario, 
por respeto a su memoria, se ofrezca a los ciudadanos un informe esclarecedor y ejemplar ${ }^{1}$.

Muchos hablarán de los vastos y diversos conocimientos que tenía Tovar. Yo solía decirle, entre asombrado y admirado, "¿Dónde tienes implantado el chip, Guillermo? No eres humano. Eres extraterrestre, confiésalo...» Podía citar de memoria al pie de la letra a los cronistas de Indias (con mención de página, según cada edición). Poco antes de su partida, reconoció por su peso, con los ojos cerrados, los libros que le presentaron en la Biblioteca "Sebastián Lerdo de Tejada», de la Secretaría de Hacienda y Crédito Público. Hablarán también de los muchos libros que escribió, verdaderas joyas del claro conocimiento y de la profunda sabiduría. Pero sólo muy pocos recordarán que cuando el terrible sismo que destrozó la ciudad de México en 1985, Guillermo Tovar, el erudito, el "niño prodigio», el sabio, el dandi siempre de corbata y chaleco, el endeble Guillermito, se fue entre los primeros a rescatar víctimas bajo los escombros y estuvo repartiendo alimentos y ropa por las calles de la amada ciudad herida en el costado.

Despreció visceralmente las vanidades del mundo. Se reía y burlaba, con conocimiento de causa, de falsos ídolos, desde poderosos multimillonarios hasta de advenedizos encumbrados. "Lo importante -decía- no es cambiar de collar, sino dejar de ser perro». Provenía de una de las familias más antiguas e importantes del virreinato, con añejas raíces en España, pero no obstante era el primero en bromear sobre ello. Se recataba en su "torre de marfil» de la colonia Roma, rodeado por sus libros, recuerdos familiares y contadísimos amigos. Desde su belvedere contemplaba con desprecio aristocrático -porque lo fue en el más amplio y completo sentido del término- los afanes y avorazados apetitos de algunos.

Generoso hasta la exageración y el despilfarro, de sus conocimientos y sus bienes, somos muchos los que podemos dar fe de forma directa de ello. A mí, además de dispensarme el privilegio de su amistad a toda prueba $-\mathrm{y}$ vaya que las hubo- me obsequió tres joyas como un Potosí cada una: La Corona mexicana o Historia de los Nueve Moctezumas (1914), los dos tomos de la primera edición del Jicotencal (1826) y un casi microscópico tomito con las Obras completas de Horacio en miniatura, editado por Didot de París en 1828, con el añadido de haber pertenecido éste al poeta cubanomexicano José María Heredia, quien lo relaciona en su lista de libros (1832) como su preferido. Todo un gran señor, con una

1 A la fecha al calce cuando reviso estas notas, no he sabido todavía nada nuevo sobre este asunto. 
elegancia insuperable, Guillermo ponía estas gemas en manos de sus amigos: "Ustedes los sabrán aprovechar mejor que yo", decía con modestia franciscana.

"Mucha gente anda equivocada conmigo -me dijo una vez-: piensan que yo soy el historiador Guillermo Tovar de Teresa... Pero ése, el erudito, murió hace mucho y lo estoy sustituyendo con su misma imagen y estampa. Soy el suplantador de ese Guillermo. Porque ahora, amigo mío, más que ser listo, lo que me interesa de veras es ser feliz». Lúdico y gozoso, le dio por frecuentar en esa etapa algunos sitios de jolgorio y música (no la llamada "clásica», de la cual era no sólo gran conocedor sino hasta "chiflador" consumado), como el famoso "Mamá Rumba" donde coincidimos varias veces, y hasta sufrió por amor al baile un doloroso percance que le afectó su frágil estructura cuando una más dispuesta que hábil señora lo sacó a bailar y se le desplomó encima, quebrándole varios huesos. "Me voy a La Habana para aprender a bailar», me soltó un día: "Allí sí saben hacerlo». Estas aventuras placenteras no impedían que de vez en cuando, como un nuevo cometa Halley, hiciera sus fulgurantes apariciones en algunas contadísimas oportunidades. Una bastante reciente, con su discurso pronunciado (al pie de la letra, no "leído", y no digo "improvisado" porque en Guillermo jamás había improvisación, pues todo lo llevaba madurando por años de infatigables lecturas y reflexiones originales) en el Museo Nacional de Antropología en ocasión memorable junto con distinguidísimos colegas, algunos de los cuales, después de aplaudirlo calurosamente le reclamaron con cariño que "no se dejara ver más". Ojalá ese discurso luminoso haya sido transcrito para que resulte perpetuado. Después de semejantes destellos deslumbrantes, Guillermo volvía a su dorado rincón, apartado del "mundanal ruido», no envidioso pero sí envidiado. Recuerdo cómo reía cuando hablando un día sobre el tema de la envidia y después de citar al infaltable Tomás de Aquino y su «tristeza del bien ajeno», se regocijó con la que le ofrecí del "gran filósofo cubano" Félix B. Caignet (autor de El derecho de nacery compositor de Frutas del Caney): «Envidia es admiración con rabia, Guillermo». "¡Tiene mucha razón: pero... cuántos “admiradores"!».

Cuando se escriba la historia definitiva de todos estos años se verá la profunda trascendencia y pertinencia de la labor incansable de Guillermo Tovar. Muchos fueron los libros que escribió pero seguramente se recordarán sobre todo dos de ellos: La ciudad de los palacios, crónica de un patrimonio perdido, que fue el "canto del cisne" de la vieja Ciudad de México, y El Pegaso, formidable ensayo de interpretación de la psicología del mexicano y de la llamada "mexicanidad», que siempre parangono junto con El perfil del hombre y la cultura en México, de 
Samuel Ramos, y El laberinto de la soledad, de Octavio Paz, trilogía imprescindible cuando se trata de penetrar en las profundidades del ser nacional. Uno de los últimos proyectos de Guillermo fue reunir en un tomo para su posible publicación por el Fondo de Cultura Económica los ensayos de varios comentaristas sobre ese libro capital: sería un muy agradecible aporte a la cultura la impresión de esa obra postrera.

Ahora alcanza la intemporalidad, "eso que llamamos, como bromeando, la gloria», el portentoso Guillermo Tovar, un Príncipe de la Cultura, después de cosechar desde su edad más temprana elogios de autoridades como Kubler, Angulo, Paz, Benítez, Teixidor, O'Gorman, Lafaye, Brading, Buxó, Tamayo, Arreola, Krause y Pacheco. Cuánto hay para agradecerle a Xavier Guzmán Urbiola quien recientemente - «en vida, hermano, en vida" como decía el Seráfico- compendiara la vida y obras de Tovar en su tributo Bosquejo biobibliográfico (DGE El Equilibrista, 2013), que fuera presentado apenas el pasado septiembre en Casa Lamm con los parabienes de personalidades como Josefina Zoraida Vázquez, Juan Ramón de la Fuente y Rafael Barajas, el Fisgón. Aquí dijo sabrosamente este último que "sería impreciso decir que Guillermo tuvo infancia, adolescencia, juventud, edad adulta y madurez; en realidad tuvo prólogo, introducción, capitulado, conclusiones y una extensa bibliografía...". Ahora habría que añadir, tristemente, que también su colofón. Se nos va Guillermo, sin un merecidísimo doctorado honoris causa de la Casa Máxima donde empeñó su temprano talento...

Se fue... pero también se queda Guillermo Tovar. Nos dejó un legado permanente, en sus días y sus obras, en su inolvidable conversación amena, erudita y generosa. Partió hacia "donde yacen los muchos», llevando un legajo de papeles antiguos bajo el brazo, airoso, sonriente, elegante, como su antecesor el también cronista Carlos de Sigüenza y Góngora, de quien tomó el ex libris: Sic itur ad astra. Sí, querido Guillermo, "por aquí hacia las estrellas». Ahora estarás, caracterizado en una constelación más, junto al "Pegaso», como el eterno Niño Tovar. Ya te echamos y mucho más echaremos de menos. Nadie podría llenar el hueco que dejaste. Quizá sólo mengua un tanto el dolor de tu precipitada partida (fuiste precoz hasta para morir, amigo; los dioses no debieron amarte tan pindáricamente), recordar tu risa abierta y tu ademán generoso, de auténtico hombre del Renacimiento, un mexicano de esos pocos que con justicia llamamos imprescindibles. Ahora permanecerás, como se dijo en la revista Proceso, incrustado "en el corazón del alma mexicana». "Duerme en paz, dulce príncipe»... 


\section{E obituarios}

Nota

Como referencias recientes sobre Guillermo Tovar de Teresa motivadas por su óbito, pueden consultarse por su carácter compendioso y entrañable:

En la revista Proceso, n. ${ }^{\circ}$ 1933, 17 de noviembre de 2013: José Emilio Pacheco (Inventario: "Guillermo Tovar de Teresa y el porvenir del pasado", pp. 74-75), con una muy completa relación de sus obras, tomada del aporte citado de Xavier Guzmán Urbiola; Judith Amador Tello y Armando Ponce, "Guillermo Tovar: conciencia de la grandeza mexicana», pp. 76-82; y dos textos esenciales de GTT: "El alma mexicana en el siglo XX» (pp. 78-79) y "Un imaginario de la Revolución Mexicana» (p. 81).

En el diario Reforma (24 de noviembre de 2013), Enrique Krause publicó su aporte: "Los regalos de Guillermo Tovar".

En el diario Milenio, Adriana Malvido ofreció su vívido artículo "Guillermo Tovar de Teresa y "Pegaso""(14 de noviembre de 2013). 